\title{
CARACTERIZAÇÃO E CLASSIFICAÇÃO DE RESÍDUO SÓLIDO “PÓ DE ROCHA GRANÍTICA” GERADO NA INDÚSTRIA DE ROCHAS ORNAMENTAIS
}

\author{
João Paulo Vargas Tavares Manhães e José Nilson França de Holanda*
}

Laboratório de Materiais Avançados, Universidade Estadual do Norte Fluminense, Av. Alberto Lamego, 2000, 28013-602 Campos dos Goytacazes - RJ, Brasil

Recebido em 14/3/07; aceito em 27/3/08; publicado na web em 26/8/08

\begin{abstract}
CHARACTERIZATION AND CLASSIFICATION OF GRANITIC ROCK POWDER SOLID WASTE PRODUCED BY ORNAMENTAL ROCK INDUSTRY. The ornamental rock industry generates huge amounts of wastes during the process of extraction and sawing of rock blocks. The ornamental rock powder waste is a non-biodegradable material, which represents the increase in environmental problem. The waste was collected from a granitic rock sawing plant located in Santo Antônio de Pádua, Rio de Janeiro. The chemical-environmental characterization and classification of the waste were done according to ABNT standards. The results showed that the granitic rock powder waste should be classified as Class II A - "No Inert", because of its high concentrations of lead, chrome, iron and manganese.
\end{abstract}

Keywords: solid waste; ornamental rock; leaching/solubilization.

\section{INTRODUÇÃO}

A revolução industrial no século XVIII inaugurou uma nova fase na história do desenvolvimento da humanidade. A partir dessa época, as atividades industriais ganharam grande destaque no desenvolvimento econômico e social. Neste cenário o objetivo principal era a geração de riqueza utilizando os recursos naturais abundantes do planeta, sem qualquer preocupação com o destino final dos resíduos gerados nos processos produtivos. ${ }^{1}$ Atualmente com o aquecimento global comprovado tem ocorrido um crescente interesse na prevenção ambiental e desenvolvimento sustentável. Assim sendo, atenção especial tem sido dada para o destino dos resíduos sólidos provenientes de atividades industrial e urbana. Isto decorre do fato de que a reciclagem ou reutilização de resíduos se constitui numa importante metodologia para utilização de resíduos como matérias-primas alternativas nos diversos setores industriais, além de preservar o meio ambiente.

O setor de mineração e beneficiamento de rochas ornamentais no Brasil tem apresentado nos últimos anos grande crescimento, gerando riqueza e empregos. O setor é baseado principalmente na extração e beneficiamento de rochas, tais como granito, mármore, gnaisse, ardósia, entre outras. As rochas ornamentais são materiais especialmente usados em construções, monumentos, arquitetura e escultura. O Brasil é um dos maiores produtores e exportadores de rochas ornamentais do mundo. ${ }^{2}$ No estado do Rio de Janeiro, a região noroeste fluminense é rica em rochas ornamentais, com enfoque para o município de Santo Antônio de Pádua. Nesta região está instalado um importante pólo de rochas ornamentais, principalmente de rochas graníticas. ${ }^{3}$

No processo de corte e beneficiamento de rochas ornamentais, em geral, são geradas enormes quantidades de resíduos abrasivos na forma de uma lama. No Brasil o destino final destes resíduos têm sido, na maioria das vezes, dispostos inadequadamente no meio ambiente, resultando em impactos ambientais que podem comprometer a flora e a fauna. Os resíduos de rochas ornamentais (lamas) podem levar rios, lagos, córregos e até mesmo os reservatórios naturais de água a altos níveis de contaminação. ${ }^{4}$ Além disso, estes resíduos quando secos se transformam num pó fino não biodegradável que provoca danos à saúde humana. ${ }^{5}$

\footnotetext{
*e-mail: jose.holanda@pesquisador.cnpq.br
}

O setor de rochas ornamentais tem se deparado nos últimos anos com a questão ambiental, principalmente relacionada com o gerenciamento de resíduos. Isto tem motivado a busca de alternativas viáveis para o destino final correto dos resíduos gerados. A construção civil representa uma área de grande potencial para absorver resíduos industriais e urbanos. ${ }^{6}$ Isto decorre do fato de que a construção civil é responsável pelo consumo do maior volume de recursos naturais. Diversos trabalhos têm sido relatados na literatura sobre a incorporação de resíduos de rochas ornamentais em materiais cerâmicos para a construção civil. ${ }^{7-11}$ Em geral estes resíduos apresentam composições química e mineralógica que, quando adicionados às formulações cerâmicas em quantidades adequadas, favorecem o processamento cerâmico. Os resíduos de rochas ornamentais são ricos em compostos fundentes $\left(\mathrm{K}_{2} \mathrm{O}\right.$ e $\left.\mathrm{Na}_{2} \mathrm{O}\right)$ que auxiliam na formação de uma fase vítrea durante o processo de sinterização. A fase vítrea é responsável pela inertização/encapsulamento de resíduos tóxicos e metais pesados.

Nesta visão, a utilização de resíduos na fabricação de produtos cerâmicos para a construção civil deve necessariamente ser acompanhada de uma avaliação dos impactos ambientais que este processo pode acarretar. Os resíduos são classificados em função de seus riscos potenciais ao meio ambiente e à saúde pública, de forma que eles possam ter manuseio e destinos apropriados. A periculosidade de resíduos poluentes é função das propriedades físicas e químicas ou infecto-contagiosas que possam apresentar. Neste contexto, um dos primeiros passos na reutilização de um resíduo em um processo produtivo é o conhecimento de seu potencial poluidor. ${ }^{12}$ Entretanto, muito pouca atenção tem sido dada à determinação do potencial poluidor de resíduos industriais e urbanos, principalmente os resíduos gerados na indústria de rochas ornamentais.

O presente trabalho é voltado fundamentalmente para o estudo da avaliação químico-ambiental de resíduo sólido de pó de rocha granítica proveniente da região de Santo Antônio de Pádua-RJ. Ênfase especial é dada aos ensaios de lixiviação e solubilidade para resíduos sólidos, visando identificar o potencial poluidor deste abundante resíduo.

\section{PARTE EXPERIMENTAL}

O resíduo de rocha granítica em forma de lama foi coletado 
diretamente no pátio de uma empresa instalada no município de Santo Antônio de Pádua-RJ. Inicialmente a amostra foi submetida a processo de secagem ao ar livre e, em seguida, foi feita secagem em estufa à temperatura de $110{ }^{\circ} \mathrm{C}$ por $24 \mathrm{~h}$. Após secagem, foram feitas as operações de destorroamento e peneiramento (- 100 mesh). Portanto, a amostra de trabalho se constitui num resíduo sólido em forma de pó fino. A composição química do resíduo sólido de pó de rocha granítica é apresentada na Tabela 1.

Tabela 1. Composição química do resíduo de rocha granítica

\begin{tabular}{lc}
\hline Composição & \% em Peso \\
\hline $\mathrm{SiO}_{2}$ & 72,17 \\
$\mathrm{Al}_{2} \mathrm{O}_{3}$ & 10,80 \\
$\mathrm{Fe}_{2} \mathrm{O}_{3}$ & 5,04 \\
$\mathrm{CaO}$ & 2,33 \\
$\mathrm{MgO}$ & 0,94 \\
$\mathrm{MnO}$ & 0,08 \\
$\mathrm{TiO}_{2}$ & 1,07 \\
$\mathrm{Na}_{2} \mathrm{O}$ & 2,34 \\
$\mathrm{~K}_{2} \mathrm{O}$ & 3,87 \\
$\mathrm{P}_{2} \mathrm{O}_{5}$ & 0,27 \\
$\mathrm{Perda}_{2}$ ao fogo $\left(1000{ }^{\circ} \mathrm{C}\right)$ & 1,08 \\
\hline
\end{tabular}

A análise mineralógica qualitativa da amostra de resíduo de rocha foi feita por difração de raios-X em um difratômetro convencional (Seifert, modelo URD 65), utilizando-se radiação de $\mathrm{Cu}-\mathrm{K} \alpha(\lambda=1,54$ $\AA$ ), na faixa angular (20) variando de $5^{\circ}$ a $70^{\circ}$. Os cartões JCPDS (Joint Committe on Powder Difraction Standards) foram usados para identificar as fases cristalinas.

A distribuição de tamanho de partículas da amostra de resíduo foi determinada por meio de uma combinação de técnicas de peneiramento e sedimentação. A morfologia das partículas foi observada por microscopia eletrônica de varredura, com voltagem de aceleração de $15 \mathrm{kV}$.

As metodologias utilizadas nas análises químico-ambiental e classificação do resíduo seguiram as recomendações da norma AWWAAPHA-WPCI ${ }^{13}$ e um conjunto de normas da ABNT (NBR - 10007; $;^{14}$ NBR - 10004; ${ }^{15}$ NBR - 10005; ${ }^{16}$ NBR - 10006). ${ }^{17}$

Inicialmente foi feita a identificação da origem do resíduo e consulta às listagens dos Anexos A e B da norma NBR - 10004. Caso o resíduo conste destas listagens, deve ser considerado como Classe I - Resíduo Perigoso. Foi verificado que o resíduo de rocha ornamental não consta das listagens. Além disso, por ser um resíduo de origem e forma de apresentação conhecida as características de inflamabilidade, corrosividade, reatividade e patogenicidade não foram estudadas. ${ }^{18}$ Desta forma, a caracterização da periculosidade ou não do resíduo foi feita através do teste de lixiviação de acordo com a norma NBR - 10005. A Tabela 2 apresenta os dados relativos ao ensaio de lixiviação. Os valores do extrato lixiviado foram comparados com os limites máximos definidos na listagem do anexo F da norma NBR - 10004. Caso o resíduo seja considerado como Classe II - Não Perigoso, então o mesmo deverá ser submetido a teste de solubilização de acordo com a norma NBR - 10006. Os valores do extrato solubilizado foram comparados com os limites

Tabela 2. Dados relativos ao ensaio de lixiviação

\begin{tabular}{ll}
\hline pH Inicial & 5,2 \\
pH Final & 5,0 \\
Tempo $(h)$ & 24 \\
\hline
\end{tabular}

máximos definidos na listagem do anexo G da norma NBR - 10004, para determinar sua classificação como Classe IIA - Não Inerte ou Classe IIB - Inerte.

\section{RESULTADOS E DISCUSSÃO}

A Figura 1 apresenta o difratograma de raios- $X$ da amostra de resíduo de rocha granítica estudado. Verifica-se que do ponto de vista mineralógico o resíduo é constituído basicamente por quartzo $\left(\mathrm{SiO}_{2}\right)$, microclina $\left(\mathrm{KAlSi}_{3} \mathrm{O}_{8}\right.$, feldspato potássico), albita $\left(\mathrm{NaAlSi}_{3} \mathrm{O}_{8}\right.$, feldspato sódico), calcita $\left(\mathrm{CaCO}_{3}\right)$ e hematita $\left(\mathrm{Fe}_{2} \mathrm{O}_{3}\right)$. Estes resultados confirmam a presença dos constituintes principais de rochas metamórficas do tipo gnaisse, que são ricas em feldspatos e quartzo. As presenças de calcita e hematita estão relacionadas principalmente à adição de granalha e óxido de cálcio como abrasivo e lubrificante no processo de corte/serragem de rochas ornamentais.

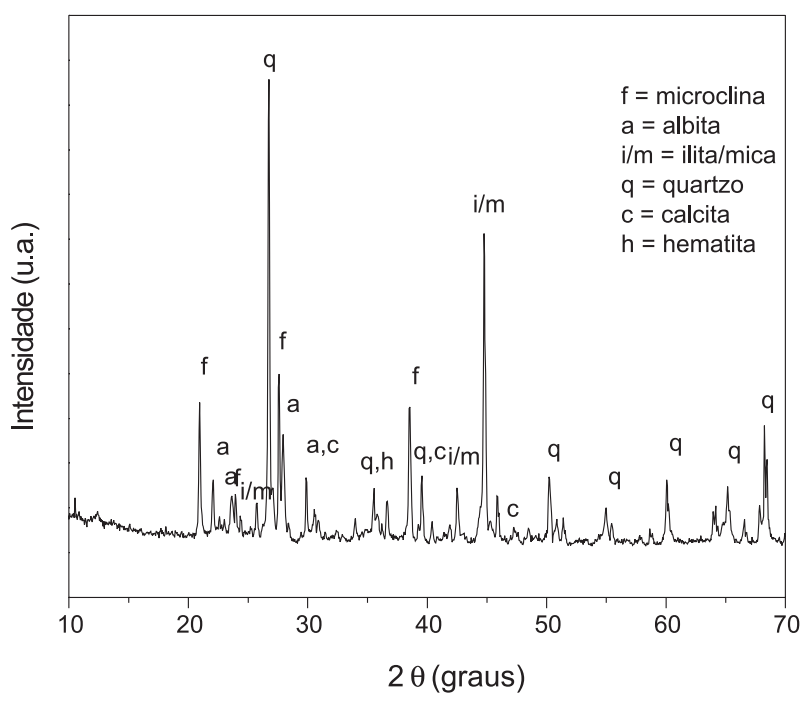

Figura 1. Difratograma de raios- $X$ do resíduo de rocha granítica

A distribuição de tamanho de partículas do resíduo é dada na Figura 2. Verifica-se que o resíduo apresenta larga distribuição de tamanho de partículas, com elevado teor de partículas acima de 20 $\mu \mathrm{m}$. Esta fração é rica em quartzo e feldspatos. O resíduo em forma de pó apresenta partículas com morfologia irregular de formato angular (Figura 3). Esta morfologia deve-se ao processo de corte/serragem dos blocos de rochas ornamentais.

A Tabela 3 apresenta os resultados obtidos para o ensaio de lixiviação da amostra de resíduo. Neste trabalho foram analisadas as concentrações de arsênio, bário, cádmio, chumbo e prata. Os resultados do extrato do teste de lixiviação indicam a presença desses elementos no resíduo de rocha granítica. No entanto, as concentrações obtidas estão abaixo dos valores limites máximos estabelecidos no anexo $\mathrm{F}$ da norma NBR - 10004. Assim sendo, está descartada a classificação do resíduo de rocha ornamental estudado como sendo Classe I - Perigoso.

$\mathrm{Na}$ Tabela 4 são apresentados os resultados relativos ao ensaio de solubilização. Os resultados mostram que o extrato solubilizado apresentou resultados acima do limite estabelecido pelo anexo $\mathrm{G}$ da norma NBR - 10004 para o chumbo $\left(0,10 \mathrm{mg} \mathrm{L}^{-1}\right)$, cromo total $(0,07$ $\left.\mathrm{mg} \mathrm{L}^{-1}\right)$, ferro $\left(5,01 \mathrm{mg} \mathrm{L}^{-1}\right)$ e manganês $\left(0,13 \mathrm{mg} \mathrm{L}^{-1}\right)$. Portanto, o resíduo de rocha ornamental estudado pode ser classificado como um resíduo de Classe II A - Não Perigoso - Não Inerte.

Os resultados das análises no extrato obtido no teste de solubilização apontam claramente que atenção especial é requerida quando da utilização de resíduo de pó de rocha ornamental como uma 


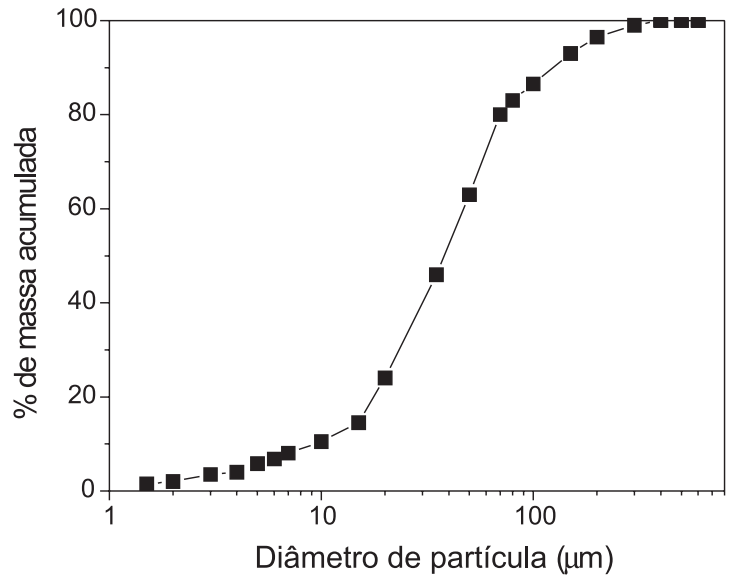

Figura 2. Distribuição de tamanho de partículas do resíduo

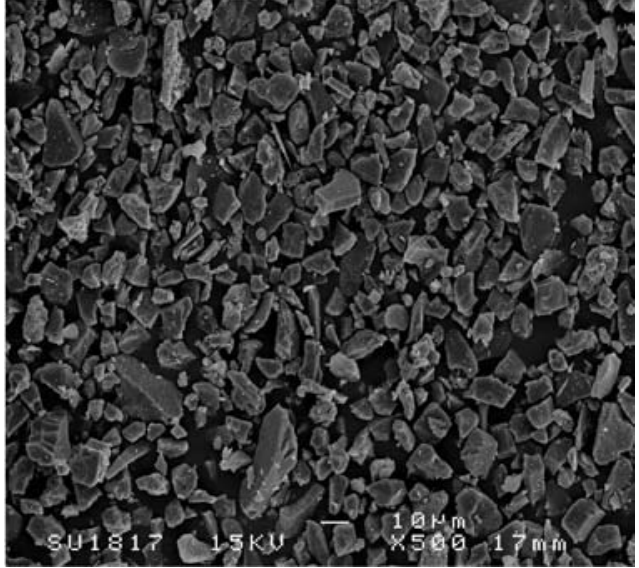

Figura 3. Morfologia das partículas do resíduo

Tabela 3. Concentração de elementos químicos no extrato do teste de lixiviação da amostra de resíduo de rocha ornamental

\begin{tabular}{lccc}
\hline Parâmetros Analisados & Concentração no Lixiviado (mg/L) & $\begin{array}{c}\text { NBR 10004 - Anexo F } \\
\text { Limite Máximo (mg/L) }\end{array}$ & $\begin{array}{c}\text { Limite de Detecção } \\
(\mathrm{mg} / \mathrm{L})\end{array}$ \\
\hline Arsênio & $<0,01$ & 1,0 & 0,01 \\
Bário & 0,08 & 70,0 & 0,01 \\
Cádmio & $<0,001$ & 0,5 & 0,001 \\
Chumbo & 0,09 & 1,0 & 0,01 \\
Cromo total & 0,06 & 5,0 & 0,01 \\
Prata & 0,02 & 5,0 & 0,001 \\
\hline
\end{tabular}

Tabela 4. Concentração de elementos químicos no extrato do teste de solubilização da amostra de resíduo de rocha ornamental

\begin{tabular}{lccc}
\hline Parâmetros Analisados & $\begin{array}{c}\text { Concentração no Solubilizado } \\
(\mathrm{mg} / \mathrm{L})\end{array}$ & $\begin{array}{c}\text { NBR 10004 -Anexo G } \\
\text { Limite Máximo (mg/L) }\end{array}$ & $\begin{array}{c}\text { Limite de Detecção } \\
(\mathrm{mg} / \mathrm{L})\end{array}$ \\
\hline Alumínio & 0,02 & 0,2 & 0,01 \\
Arsênio & $<0,01$ & 0,01 & 0,01 \\
Bário & 0,09 & 0,7 & 0,01 \\
Cádmio & $<0,01$ & 0,005 & 0,001 \\
Chumbo & 0,10 & 0,01 & 0,01 \\
Cobre & 0,04 & 2,0 & 0,01 \\
Cromo total & 0,07 & 0,05 & 0,01 \\
Dureza $\left(\mathrm{mg} \mathrm{CaCO}_{3} / \mathrm{L}\right)$ & 101 & 500 & 0,1 \\
Ferro & 5,01 & 0,3 & 0,01 \\
Manganês & 0,13 & 0,1 & 0,01 \\
Nitratos & $<0,01$ & 10,0 & 0,01 \\
Prata & $<0,01$ & 0,05 & 0,01 \\
Sulfatos & 53 & 250,0 & 1,0 \\
Surfactantes & $<0,2$ & 0,5 & 0,2 \\
Zinco & 0,03 & 5,0 & 0,01 \\
\hline
\end{tabular}

matéria-prima alternativa para fabricação de produtos cerâmicos para construção civil.

Nos casos do ferro e manganês não há problemas maiores, uma vez que esses elementos fazem parte da composição de diversas matérias-primas cerâmicas convencionais. No entanto, a presença desses elementos pode contribuir para alterar as características físicas da qualidade das águas incorporando, eventualmente, cor e turbidez. Apesar disso, não há inconveniência do ponto de vista sanitário. Em relação ao chumbo e ao cromo total há sério risco de contaminação do ambiente devido à possibilidade de solubilização em água.

Um aspecto de grande importância a ser também considerado é que produtos cerâmicos para construção civil como tijolos, blocos cerâmicos e telhas são geralmente fabricados numa temperatura da ordem de 950
${ }^{\circ} \mathrm{C} .{ }^{19}$ Esta temperatura é relativamente baixa para promover a completa inertização e imobilização do resíduo na matriz cerâmica sinterizada. Isto se deve a baixa quantidade de fase vítrea formada. Outro aspecto é o fato conhecido de que a maioria das cerâmicas e olarias no Brasil fabrica seus produtos numa temperatura de queima bem inferior a $950{ }^{\circ} \mathrm{C}$.

\section{CONCLUSÕES}

O resíduo sólido de pó de rocha granítica foi caracterizado e classificado como resíduo Classe IIA - Não Inerte, segundo a norma NBR - 10004. Esta classificação é decorrente da seguinte situação: presença de chumbo, cromo total, ferro e manganês acima dos limites máximos permitidos para o teste de solubilização. De forma que é 
imperativa a realização de estudos de impactos ambientais quando da incorporação de resíduos de rochas ornamentais em produtos cerâmicos para construção civil.

\section{AGRADECIMENTOS}

Ao CNPq pelo apoio ao desenvolvimento deste trabalho e ao Dr. G. Parente pela análise morfológica.

\section{REFERÊNCIAS}

1. Toffler, A.; A Terceira Onda, 25ª ed., Record: São Paulo, 2001.

2. Menezes, R. R.; Ferreira, H. S.; Neves, G. A.; Lira, H. L.; Ferreira, H. C.; J. Eur. Ceram. Soc. 2005, 25, 1149.

3. Moreira, J. M. S.; Manhães, J. P. V. T.; Holanda, J. N. F.; Cerâmica 2005 , $51,180$.

4. Simsek, C.; Karaca, Z.; Gemici, U.; Gunduz, O.; Fresenius Environ. Bull. 2005, 14, 1013.

5. Rego, G.; Martinez, C.; Quero, A.; Blanco, T. P.; Borquea, J. M.; Medicina Clínica 2001, 116, 291.

6. Giffoni, P. O.; Lange, L. C.; Engenharia Sanitária e Ambiental 2005, $10,129$.

7. Hernández-Crespo, M. S.; Rincón, J. M.; Ceram. Int. 2001, 27, 713.
8. Filho, H. F. M.; Polivanov, H.; Barroso, E. V.; Mothé, C. G.; Thermochim. Acta 2002, 392/393, 47.

9. Torres, P.; Fernandes, H. R.; Agathopoulos, S.; Tulyaganov, D. U.; Ferreira, J. M. F.; J. Eur. Ceram. Soc. 2004, 24, 3177.

10. Souza, L. P. F.; Mansur, H. S.; Journal of Materials Processing Technology 2004, 145, 14.

11. Segadães, A. M.; Carvalho, M. A.; Acchar, W.; Appl. Clay Sci. 2005, 30, 42.

12. John, V. M.; Zordan, S. E.; Waste Management 2001, 21, 213.

13. Apha; Standard Methods for the Examination of Water and Wastewater, $20^{\text {th }}$ ed., Apha: Washington, 1998.

14. ABNT; Amostragem de Resíduos Sólidos, ABNT: Rio de Janeiro, 2004, (norma técnica NBR - 10007).

15. ABNT; Resíduos Sólidos - Classificação, ABNT: Rio de Janeiro, 2004, (norma técnica NBR - 10004).

16. ABNT; Procedimento para Obtenção de Extrato de Lixiviado de Resíduos Sólidos, ABNT: Rio de Janeiro, 2004, (norma técnica NBR 10005).

17. ABNT; Procedimento para Obtenção de Extrato de Solubilizado de Resíduos Sólidos, ABNT: Rio de Janeiro, 2004, (norma técnica NBR 10006).

18. Oliveira, M. R. C.; Martins, J.; Quim. Nova 2003, 26, 6.

19. Santos, P. S.; Ciência e Tecnologia de Argilas, Ed. Edgard Blücher Ltda.: São Paulo, 1989, vol. 1. 